\title{
Review
}

\section{Projections of the climate potential for tourism at local scales: application to Platja de Palma, Spain}

\author{
A. Amengual, ${ }^{\mathrm{a}, \mathrm{b} *}$ V. Homar, ${ }^{\mathrm{a}}$ R. Romero, ${ }^{\mathrm{a}} \mathrm{S}$. Alonso ${ }^{\mathrm{a}, \mathrm{b}}$ and C. Ramis ${ }^{\mathrm{a}}$ \\ a Grup de Meteorologia, Departament de Física, Universitat de les Illes Balears, Palma de Mallorca, Spain \\ b Departament de Recerca en Canvi Global, Institut Mediterrani d'Estudis Avançats, Palma de Mallorca, Spain
}

\begin{abstract}
Primary socioeconomic activities in the System of Platja de Palma (SPdP), located in the southwestern coast of Mallorca, Spain, are beach-based holidays and, therefore, are very closely linked to climate. The social, economic and environmental adaptation that this region must make in the mid- and long-term period has to take into account the changes in the tourist potential when the climate changes. A second-generation climate index for tourism (CIT) has been adopted to measure tourism potential under the present and possible future climatic conditions. CIT is a theoretically based and empirically derived index that allows assessing the sun, sea and sand (3S) weather resource. Daily observed series of $2 \mathrm{~m}$ maximum temperature, precipitation, $2 \mathrm{~m}$ relative humidity, cloud cover and $10 \mathrm{~m}$ wind speed have been used to derive the present climate potential for tourism. For future projections, daily averaged meteorological variables have been obtained from a set of regional climate models (RCMs) within the European ENSEMBLES project. The adoption of a multimodel ensemble strategy allows quantifying the uncertainties arising from model errors and boundary conditions. To use CIT values based on RCM data properly at local scales, a quantile-quantile adjustment has been applied. Results show a significant increase in the annual frequency of days with acceptable conditions together with a slightly increment for the ideal climate perceptions at the expense of decreasing unacceptable categories. For the summery peak season, ideal conditions are projected to decrease from mid-century favouring acceptable categories. However, an almost general increase for both classes is anticipated in spring and autumn throughout the century. That is, higher frequencies of optimal climate perceptions for carrying out $3 \mathrm{~S}$ outdoors activities are expected to shift from the peak to shoulder seasons. Therefore, climate change would result in a major impact for the current seasonally adjusted service sector in SPdP. With this information at hand, policy makers and the team of experts planning its socioeconomic future can respond more effectively to the demanding challenge of local adaptation to climate change by implementing adaptation and mitigation strategies to the tourist sector. Copyright (C) 2011 Royal Meteorological Society
\end{abstract}

KEY WORDS climate potential for tourism; climate change; regional modeling; ensemble strategy; statistical adjustment; local scale

Received 3 February 2011; Revised 18 July 2011; Accepted 19 July 2011

\section{Introduction}

Tourism is one of the largest economic sectors worldwide and, for many European Mediterranean countries, beach-based holidays are a key resource income source. Sun, sea and sand (3S) tourism currently is based on well defined subjective perceptions of warm and sunny climates as suitable environments for spending holidays (Aguiló et al., 2005). Specifically, $3 \mathrm{~S}$ tourism is strongly linked to a diverse set of atmospheric variables such as temperature, rainfall, relative humidity, cloudiness (i.e. hours of sunshine) and wind speed (De Freitas, 1985, 1990). Other natural assets as beaches' environment, land- and seascapes or biodiversity generally are important elements for these outdoor activities as well.

\footnotetext{
* Correspondence to: A. Amengual, Dept. de Física, Universitat de les Illes Balears, 07122 Palma de Mallorca, Spain.

E-mail: arnau.amengual@uib.es
}

Global environmental change threatens these conditions. Further, $3 \mathrm{~S}$ tourist transportation activities directly affect climate change through greenhouse gas emissions, and $3 \mathrm{~S}$ tourism is especially sensitive to climate change impacts. Moreover, the natural variability of the weather parameters determines the seasonality in the industry for many regions worldwide. As an example, the European seasonal contrast acts as a pull and push factor for the peak summery demand of holidays in Europe (Viner, 2006).

The direct and indirect effects of climate change on tourism could vary with location. Observations show that the global mean air surface temperature has increased notably during the twentieth century. The rate of this global warming for the 1979-2005 period is estimated to be close to $2.7^{\circ} \mathrm{C}$ per century. For the Mediterranean region, the rate of global warming has been between 2.5 and $3.5^{\circ} \mathrm{C}$ per century (IPCC, 2007). Associated with this has been a redistribution of rainfall and other 


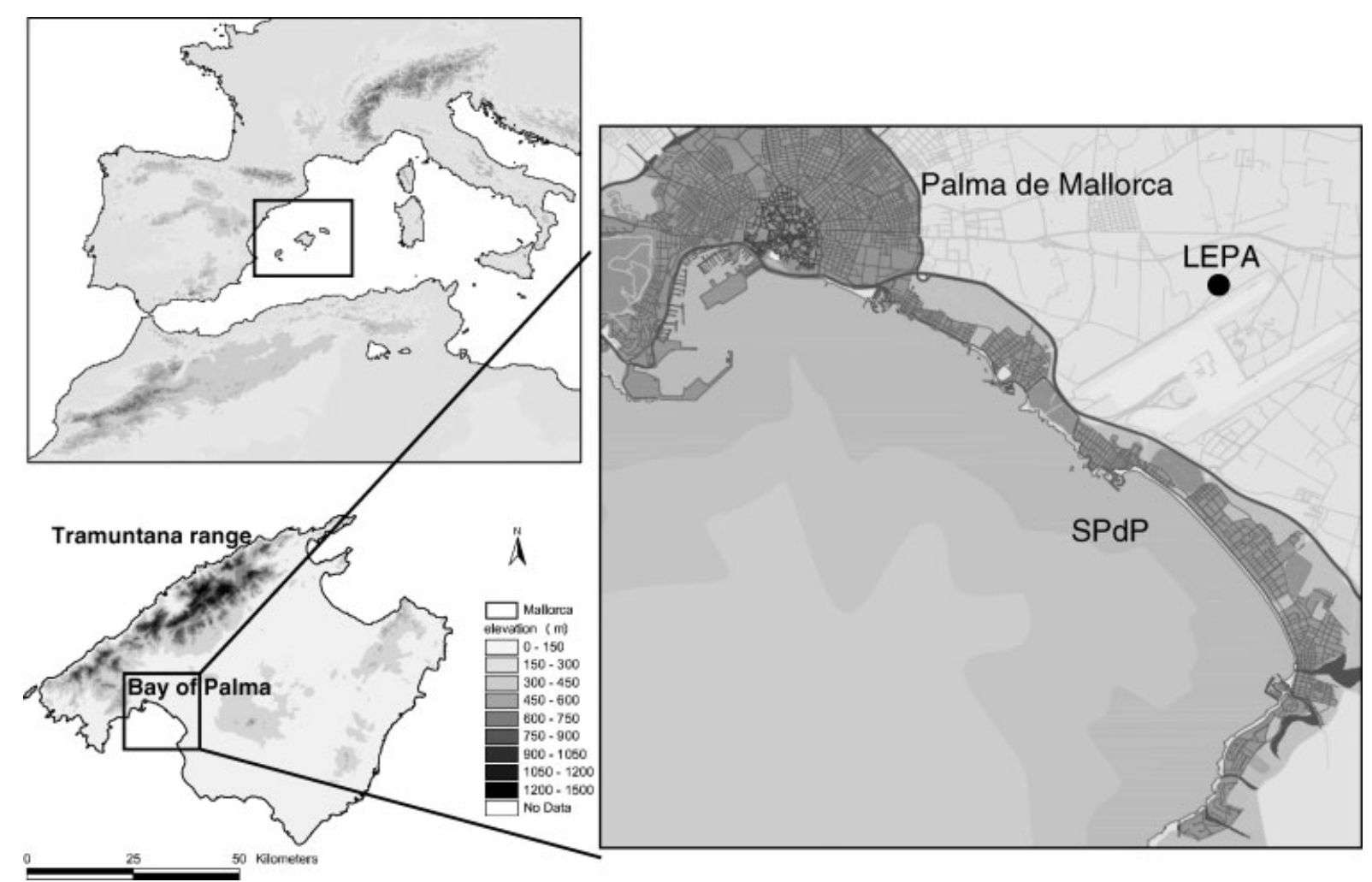

Figure 1. Geographical location of the System of Platja de Palma (SPdP) in the western Mediterranean region. It is located in Mallorca, the largest of the Balearic Islands. Major topographic features of the entire region are shown. The location of the automatic weather station (denoted LEPA) is also displayed.

atmospheric variables (e.g. pressure, wind, cloudiness). In the Mediterranean, a rainfall decrease has been observed between 5 and 20\% from 1901 to 2005 (IPCC, 2007). The direct impact of an increase in temperatures for high latitudes could result in a poleward shift in the atmospheric conditions for summery recreation while warm regions could present inappropriate weather conditions (Amelung et al., 2007). Indirect effects over regions that are highly dependent on tourism could include changes in the availability of drinkable water, energy prices, landand seascapes or travel costs (IPCC, 2007).

Several works have stated optimal average temperatures for general tourism activities, but without contemplating the dominance of other crucial atmospheric variables when assessing the weather resource (Gössling and Hall, 2006). For example, Lise and Tol (2002) studied tourism under climate change and found that tourists perceive $21.0^{\circ} \mathrm{C}$ as an optimal average temperature for the warmest month of the year. Maddison (2001) identified $30.7^{\circ} \mathrm{C}$ as the maximum daily temperature preferred by the British on their choice of recreation destinations. Bigano et al. (2006) pointed out that the optimal holiday destination has an average annual temperature of roughly $16.2^{\circ} \mathrm{C}$, which is within the current range of the Mediterranean countries. These and other studies indicate effects on travel behaviour and tourism flows that are a consequence of altering the weather perception as less or more comfortable. Such impacts are a general concern for state, regional and local policy makers. Although climate change is a problem of global causes and consequences, its impacts also become apparent locally. Therefore, to address these issues on the local scale is of considerable social, economic and environmental interest.

The Balearic Islands are located in the western Mediterranean area and are one of world's leading destinations for the $3 \mathrm{~S}$ tourism (Aguiló et al., 2005). The System of Platja de Palma (SPdP) is placed in the southwestern Majorcan coastal area, Spain (Figure 1), and is the primary tourist resort in the Balearics. The predominant economic activity is a beach-based mass tourism model. The Consortium of Platja de Palma - an agreement signed by the Balearic Islands Government and the Spanish Ministry of Industry, Commerce and Tourism - seeks to establish a different vision and consider different tourism models. Major guidelines for the Consortium include as key issues: sustainability, climate and global change and social and residential cohesion (further information can be found at http://consorcioplayadepalma.es). Therefore, an important issue for the Consortium is to assess climate change impacts on the tourism potential of SPdP for the later implementation of mitigation and adaptation strategies. Within this framework, we assess the present climate potential for 3S tourism in SPdP; and explore its possible future evolution as a result of climate change.

The close relationship between weather resource and $3 \mathrm{~S}$ recreation can be seen through a climate index for tourism. We employ a second-generation climate index 
for tourism (CIT), a theoretically based and empirically adjusted indicator that was developed specifically to rate the weather resource for $3 \mathrm{~S}$ outdoor activities. However, some limitations in testing the CIT were also reported: the index was examined for a relatively narrow tourist-marked segment over a restricted spatial coverage (De Freitas et al., 2008). To compute the CIT, we use observed daily series for maximum temperature, precipitation, relative humidity, cloudiness and wind speed. Regarding projections, simulated daily data have been provided by several regional climate models (RCMs) run under the A1B emissions scenario (SRES; Nakicenovic et al. 2000). A challenge such local analyses pose is the need for quantitative estimates at very small spatial and temporal scales. To this end, we apply a novel quantile-quantile correction to the continuous CIT cumulative distribution functions ( $\mathrm{CDFs}$ ) to assess climate change impacts on the future climate potential of SPdP (Amengual et al., (unpublished)). The rest of the paper is structured as follows: Section 2 presents a brief description of the climatic and socioeconomic features of the study area; Section 3 summarizes the observed and simulated databases used and provides an evaluation of the quantile-quantile adjustment; Section 4 exposes the observed and projected annual, seasonal and monthly mean regimes of the climate potential for tourism; and finally, Section 5 reviews the main results and offers some additional remarks.

\section{Climatic and socioeconomic features of the study area}

Climatic characteristics in the Balearic Islands are typical of the western Mediterranean region. The islands are affected by a wide range of synoptic flows and both the Mediterranean Sea and the Atlantic Ocean, strongly influence and modulate their climate. In summer, the synoptic situation is dominated by the Azores highpressure system, which results in a sustained increase of both air and sea surface temperatures. Furthermore, precipitation is scarce during this season, resulting in a moderate drought period. In early autumn, the eastward extension of the Azores high-pressure system moves equator-wards. This fact facilitates the arrival of midto upper-level Atlantic cold air masses. Heavy rainfalls are observed commonly during this season as a result of the confluence of the Atlantic cold air masses, the presence of moist and warm Mediterranean air at low levels, the relatively high sea surface temperature and the complex orography of the region (Tudurí and Ramis, 1997; Romero et al., 1999; Amengual et al., 2008). The passage of cold fronts mainly affects the northern side of Mallorca and the island of Menorca, resulting in intense northerly to westerly winds. These areas have the largest number of days with strong winds, cloudiness and rain across the Balearics with annual precipitation amounts close to $600-700 \mathrm{~mm}$. In the southern part of the islands, rainy days are linked to moist easterly flows. These are typically convective in character and can have high precipitation rates, mainly in autumn, but with occasional events in spring and winter (Romero et al., 1999). For the Balearics, the mean annual rainfall is roughly $560 \mathrm{~mm}$ (Homar et al., 2010).

Mallorca is characterized by an irregular distribution of mountain ranges and plains and, therefore, constitutes an excellent example of a region with complex topography. The Tramuntana range, located in the northwestern part of the island, presents the highest elevations and has maximum heights close to $1500 \mathrm{~m}$ (Figure 1). The complex orography of Mallorca together with an irregular coastline and its inherent insular characteristics (e.g. summer sea breeze regimes) result in a relatively high climatic diversity (Guijarro, 1986). That is, in the Tramuntana mountainous area, mean annual rainfall amounts can range from 1000 to $1500 \mathrm{~mm}$, whereas in the southern coastline only $50 \mathrm{~km}$ away, it barely exceeds $350 \mathrm{~mm}$. Temperatures are strongly dependent on altitude and distance to the sea as well. Furthermore, the Spanish Mediterranean area is quite often affected by the incursion of Siberian and Saharan - and occasionally, Arctic - air masses resulting in severe cold and heat waves. Mean annual minimum and maximum temperatures in the Balearic Islands are 12.8 and $21.8^{\circ} \mathrm{C}$, respectively (Homar et al., 2010).

The SPdP is located in the southwestern coastal part of Mallorca, adjacent to the city of Palma (Figure 1). The annual average of overnight stays spent in the whole Palma county was over 8 million during the 1999-2008 period, including both hotels and tourist apartments (INE, 2009). In particular, SPdP is the main tourist resort in the Balearics: it can host 40000 visitors per night, with a total of 1.2 million nights spent per year. Its main socioeconomic activities rely on the service sector, although it is also an important residential area - with 34000 permanent inhabitants - owing to its proximity to Palma, the province capital. It has $10 \mathrm{~km}$ of coastline, mainly consisting of sand beaches, and the dominant leisure activities are those related with the $3 \mathrm{~S}$ mass tourism model. However, the SPdP also offers other attractions such as: nautical and sea sport entertainment, shopping, and even business, cultural and gastronomical services as a result of its closeness to the ancient centre of the capital.

\section{Database and methods}

\subsection{Input data and climate index for tourism}

Observations used in this study were records from an automatic weather station deployed in 1973 by the Spanish Meteorological Agency (AEMET) at Palma's international airport (denoted by LEPA; $39.37^{\circ} \mathrm{N}, 2.43^{\circ} \mathrm{E}$ ). No significant changes have occurred near this station, since it operates at the head of the first runway, far from any urban development (Figure 1). Therefore, local effects from urbanisation, such as heat island warming or precipitation sheltering are negligible (Gual et al., 2002). Further, its proximity to the SPdP - less than $4 \mathrm{~km}$ - makes it a dataset well suited to address the objectives of this 
work. To determine the climate potential for tourism in SPdP, the complete daily observed series of $2 \mathrm{~m}$ maximum temperature, accumulated precipitation, $2 \mathrm{~m}$ mean relative humidity, mean cloud cover and $10 \mathrm{~m}$ mean wind speed for the entire 1973-2008 period (36 years) have been used.

Nowadays, climate indices for tourism include the influence of weather conditions on human comfort. The subjective perception of the weather resource does not deal exclusively with an optimal range of daily temperatures, but also with the effects of relative humidity, wind speed, short- and long-wave radiation and cloudiness. Human comfort depends on non-environmental effects as the level of activity or clothing as well. We account for all these factors by using a second generation climate index for tourism (CIT), which expresses the integrated body-atmosphere energy balance as a thermal sensation (De Freitas et al., 2008). The CIT has been designed specifically to assess the weather resource for $3 \mathrm{~S}$ activities. Originally, climate indices for tourism only considered a single element, the thermal facet. Later, a more elaborate indicator, the Tourism Climate Index (TCI; Mieczkowski, 1985), accounted for several facets of the weather. TCI was theoretically developed to evaluate the weather resource for general tourism activities and it was based on monthly average climatic variables, but was not validated against human perception. On the other hand, CIT is theoretically sounded, but also empirically tested. It combines daily weather variables by merging their thermal (T), aesthetic (A) and physical (P) aspects. These features are combined in a weather typology matrix that determines the $3 \mathrm{~S}$ subjective comfort perception by

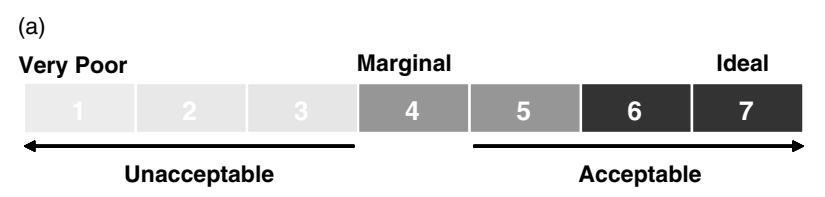

(b)

\begin{tabular}{|c|c|c|c|c|c|}
\hline \multicolumn{2}{|c|}{$\begin{array}{c}\text { ASHRAE scale } \\
\text { TSN [T] }\end{array}$} & \multirow{2}{*}{$\begin{array}{c}\text { Cloud } \\
(<45 \%) \\
{[A]} \\
4\end{array}$} & \multirow{2}{*}{$\begin{array}{c}\begin{array}{c}\text { Cloud } \\
(\geq 45 \%) \\
{[A]}\end{array} \\
\qquad 3\end{array}$} & \multirow{2}{*}{$\begin{array}{c}\begin{array}{c}\text { Rain } \\
(>3 \mathrm{~mm}) \\
{[\mathrm{P}]}\end{array} \\
2\end{array}$} & \multirow{2}{*}{$\begin{array}{c}\begin{array}{l}\text { Wind } \\
(\geq 6 \mathrm{~m} / \mathrm{s}) \\
{[\mathrm{P}]}\end{array} \\
\frac{3}{3}\end{array}$} \\
\hline Very hot & $(+4)$ & & & & \\
\hline Hot & $(+3)$ & 6 & 5 & 2 & 4 \\
\hline Warm & $(+2)$ & 7 & 5 & 2 & 4 \\
\hline Slightly warm & $(+1)$ & 6 & 4 & 1 & 4 \\
\hline Indifferent & (0) & 5 & 3 & 1 & 2 \\
\hline Slightly cool & $(-1)$ & 4 & 3 & 1 & 2 \\
\hline Cool & $(-2)$ & $3^{*}$ & $2^{*}$ & $1^{*}$ & $2^{*}$ \\
\hline Cold & $(-3)$ & $2^{*}$ & $2^{*}$ & $1^{\star}$ & $1^{*}$ \\
\hline Very cold & $(-4)$ & $1^{*}$ & $1^{*}$ & $1^{*}$ & $1^{*}$ \\
\hline
\end{tabular}

Figure 2. (a) Climate index for tourism (CIT) rating scale, and (b) the weather typology matrix, adapted from De Freitas et al. (2008), in order to derive climate satisfaction rating classes. Asterisk denotes the elements of the matrix filled by the authors. ranking the weather resource (Figure 2). Furthermore, the index also recognizes the dominating effects of these elements when they exceed certain thresholds. That is, the CIT assumes that the integrated effect of some particular weather condition is not just the sum of its various facets (Figure 2; De Freitas et al., 2008).

The CIT assigns the weather resource for beach recreation using a scale from very poor (i.e. CIT $=1$, unacceptable) to very good (i.e. CIT $=7$, optimal; Figure 2). The CIT addresses the environmental and physiological variables: solar heat load, heat loss by convection (i.e. wind), evaporation (i.e. sweating), short- and longwave radiation exchanges and metabolic heat (i.e. activity level) through the thermal element. The aesthetic and physical aspects refer to the sky condition and to the effects of precipitation or strong wind, respectively (De Freitas et al., 2008). Originally, the weather typology matrix did not rate climate potential for thermal conditions below slightly cool owing to their inappropriateness for beach-based holidays. However, we rate those CIT values that were left blank to avoid dealing with unavailable data (see Figure 2). Filling these gaps will not change the results, since all the chosen numerical codes lie within the unsatisfactory class. Furthermore, original thresholds for the aesthetic facet have been modified slightly, that is, cloud from $\leq 40$ to $<45 \%$, and from $\geq 50$ to $\geq 45 \%$, to avoid inconsistencies with the available observations (Figure 2). Thermal sensation for the CIT thermal element has been computed by using the RayMan model (Matzarakis and Rutz 2007a).

RayMan accounts for the body-atmosphere energy budget schemes and yields the mean radiant temperature $\left(T_{m r t}\right) . T_{m r t}$ is the most important parameter affecting the human energy balance during sunny weather conditions. The model derives the following thermal indices from the mean radiant temperature: the Predicted Mean Vote (PMV), the Physiologically Equivalent Temperature (PET) and the Standard Effective Temperature (SET; Matzarakis and Rutz, 2007a; Matzarakis et al., 2007b). $T_{m r t}$ is obtained by setting up the following daily meteorological parameters in Rayman: maximum temperature, relative humidity, wind speed, short- and long-wave radiation and cloud cover. We use the daily maximum rather than the daily mean temperature in RayMan as a more accurate proxy for the actual temperature, since most $3 \mathrm{~S}$ tourism takes place around midday, when the temperature is near its maximum for the day. RayMan also includes the subsequent thermo-physiological parameters: human activity, body heat production and heat transfer resistance of clothing. The PET has been employed to obtain the thermal facet of the weather. Finally, computing the CIT requires expressing this feature as a thermal sensation by using the standard nine-point ASHRAE scale (ASHRAE, 2004; Figure 2). Note that PET has been computed by considering the following standard personal and thermophysiological parameters: height $=1.75 \mathrm{~m}$; weight $=$ $75 \mathrm{~kg}$; age $=35$ years; sex $=$ male; clothing $=0.1$ clo and activity $=46 \mathrm{~W}$. 
Table I. List of transient RCM experiments driven within the ENSEMBLES European project for the 1951-2100 period. Note that all the models have a spatial resolution of $25 \mathrm{~km}$ and have been run under the A1B SRES.

\begin{tabular}{|c|c|c|c|}
\hline Driving GCM & $\mathrm{RCM}$ & Acronym & Institute \\
\hline ECHAM5 & RCA3 & C4IRCA3 & C4I \\
\hline ARPEGE & HIRLAM & $\begin{array}{l}\text { DMI- } \\
\text { HIRLAM5 }\end{array}$ & DMI \\
\hline ECHAM5 & HIRLAM & $\begin{array}{l}\text { DMI- } \\
\text { HIRLAM5 }\end{array}$ & DMI \\
\hline $\mathrm{BCM}$ & HIRLAM & $\begin{array}{l}\text { DMI- } \\
\text { HIRLAM5 }\end{array}$ & DMI \\
\hline HadCM3 & CLM & ETHZ-CLM & ETHZ \\
\hline ECHAM5 & $\mathrm{RegCM}$ & ICTP-REGCM & ICTP \\
\hline ECHAM5 & RACMO & $\begin{array}{l}\text { KNMI- } \\
\text { RACMO }\end{array}$ & KNMI \\
\hline HadCM3 & HadRM3Q0 & $\begin{array}{l}\text { METO-HC- } \\
\text { HadCM3Q0 }\end{array}$ & $\mathrm{HC}$ \\
\hline HadCM3 & HadRM3Q3 & $\begin{array}{l}\text { METO-HC- } \\
\text { HadCM3Q3 }\end{array}$ & $\mathrm{HC}$ \\
\hline HadCM3 & HadRM3Q16 & $\begin{array}{l}\text { METO-HC- } \\
\text { HadCM3Q16 }\end{array}$ & $\mathrm{HC}$ \\
\hline $\mathrm{BCM}$ & RCA & SMIRCA & SMHI \\
\hline ECHAM5 & RCA & SMIRCA & SMHI \\
\hline HadCM3 & RCA & SMIRCA & SMHI \\
\hline
\end{tabular}

\subsection{Quantile-quantile adjustment approach}

We use the regional simulations database available from the ENSEMBLES European project in order to explore the future climate potential for tourism. Daily-averaged climate data from 13 different RCMs run from 1951 to 2100 for the A1B SRES emissions scenario have been considered (Table I). These experiments were performed by using a $25 \mathrm{~km}$ horizontal grid-length resolution that spans Europe, and includes the easternmost part of the Atlantic ocean, northern Africa and western Asia. We adopt a multimodel ensemble approach to evaluate the uncertainties arising from model errors - i.e. in the representation of the physical processes within $\mathrm{RCMs}$ - and the inaccuracies found in their boundary conditions as well (Table I; Hewitt and Griggs, 2004; further information at http://ensembles-eu.metoffice.com). Daily averaged simulated variables for each model have been bilinearly interpolated to LEPA from the four nearest grid points (Akima, 1978 and 1996) in order to derive CIT. To properly use this indicator at such local scales, we apply the quantile-quantile correction described in detail in Amengual et al. (unpublished) to each individual CIT series.

To apply the adjustment, we consider a control period in the twentieth century with observed and simulated daily data as well as successive future simulated intervals of the same length. Then, these data are used to build the cumulative distribution functions (CDFs) of the variable under analysis, in this case CIT. The number of quantiles used to construct these CDFs will be the number of days included in the above periods. Then, the difference between each future simulated CDF and the control simulated CDF is computed for each quantile of the distribution, noted herein as $i_{t h}$-difference. A basic correction approach would consist of simply adding these

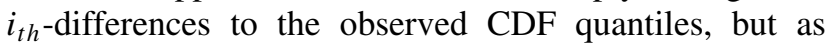
explained in Amengual et al. (unpublished), our method first splits these $i_{t h}$-differences into two components (Figure 3(a) and (b)): the average difference between both distributions (a constant value) and the perturbation of the $i_{t h}$-difference with respect to the previous average (an $i_{t h}$-dependent positive or negative value). And then, to produce the projected CDF, each component is added to the observed CDF quantile with a weighting factor that depends on the model error. Specifically, the weighting factor for the average difference is the ratio between observed and simulated control mean CIT values, and the weighting factor for the $i_{t h}$-perturbation is the ratio between observed and simulated standard deviations. Note that for the special case of a perfect model, both weighting factors would be equal to 1 and the adjustment method would exactly converge to the abovementioned basic correction approach.

To illustrate the performance of this adjustment, we use the Weibull distribution to generate a set of theoretical probability distribution functions (PDFs) and associated CDFs for a daily observed and simulated physical variable. Figure 3(a) and (b) show the correction in the mean state, variability and distribution shape of the projected CDF. As explained in Amengual et al. (unpublished), the changes between the control (RCM control) and future (RCM future) daily simulated data are locally rescaled (i.e. quantile by quantile) in basis of the observed CDF for the same control period (OBS control; baseline). Then, these changes are transfered to this baseline in order to obtain the projected data (Projected), thus permitting to reconcile each RCM with the observed climate. Figure 3(c) depicts the effects of applying this technique on the PDFs of the simulated data. The use of the quantile-quantile adjustment corrects in the future PDF the positive bias and excessive variability found in the control period for this hypothetical RCM.

The discrete distribution of daily CIT scores based on each individual RCM output has been transformed into a continuous distribution using a stochastic transformation centred on each discrete value in order to apply the statistical adjustment between a 15-year control period (1973-1987) and successive 15-year simulated time-slices. We choose periods of 15 years for two reasons. First, owing to the temporal limitation of the observed database range comprising 36 years, a part of which is reserved for validation purposes. And second, we consider this length to be a compromise between series large enough to have climatological meaning - the statistical population is $N=5478$ - but short enough to allow by comparing the CDFs of successive 15 -year intervals starting in 2010, an effective isolation of any climate change signal along the twentyfirst century. For the sake of simplicity, we label the CIT scores as: observed when derived from observations, raw or uncalibrated when based on RCM outputs without using the statistical 

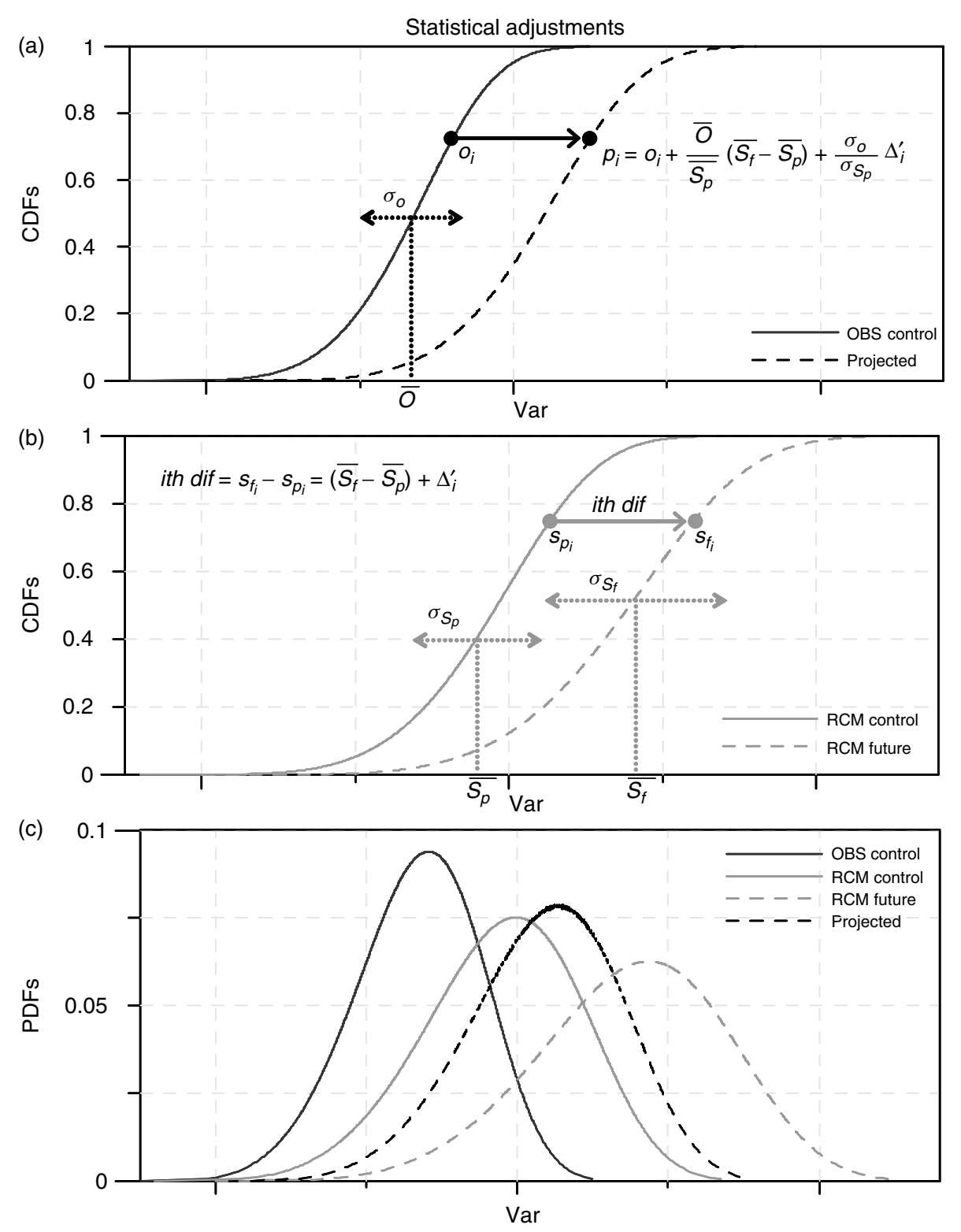

Figure 3. Theoretical CDF ((a) and (b)) and PDF (c) distributions of a daily physical variable are shown for an observed control (OBS control), control simulated (RCM control), future simulated (RCM future) and the calibrated data (Projected). Note that $\bar{O}$ is the average of the observed control period data, whereas $\overline{S_{p}}$ and $\overline{S_{f}}$ are the averages of the control and future simulated data periods, respectively. $\sigma_{o}, \sigma_{s_{p}}$ and $\sigma_{s_{f}}$ denote their standard deviations. $\Delta_{i}$ ' is the $i_{t h}$-perturbation. The $i_{t h}$ projected quantile $\left(p_{i}\right)$ is obtained by applying the mathematical expression shown in (a). $o_{i}, s_{p i}$ and $s_{f i}$ are the $i_{t h}$ observed, control simulated and future simulated quantiles, respectively.

adjustment, and calibrated or projected when obtained after applying the calibration technique.

We evaluate the performance of the quantile-quantile correction by comparing the raw and calibrated CIT distributions for the multimodel mean against the observed CIT distribution. For this purpose, we select a 15 -year independent validation period spanning from 1994 to 2008. The following categorisations are used to simplify the discussion of the performance of the adjustment and the subsequent results in next sections: $\mathrm{CIT}=1,2,3$ : unacceptable; CIT $=4,5$ : acceptable; and CIT $=6,7$ : ideal conditions, respectively (De Freitas et al., 2008). An overall improvement of the calibrated versus uncalibrated CDFs is seen for the CIT (Figure 4(a)). That is, the calibrated and observed distributions are almost identical for the unacceptable conditions. A small difference is found between the calibrated and observed percentiles for the acceptable perception, but the uncalibrated CIT biases are still remarkably higher. The benefit of the quantile-quantile technique does not seem to be so evident for the ideal category. Even so, Table II shows that the errors found in the raw CIT values are significantly lower in terms of the percentile-wise mean absolute (MAE) and root mean square (RMSE) errors.

The quantile-quantile (Q-Q) plot emphasizes the benefits of the statistical correction as well (Figure 4(b)). The calibrated CIT data show a more linear behaviour and are generally close to the diagonal that represents a perfect correspondence. Furthermore, the adjustment corrects the excessive spread found in raw CITs for the 

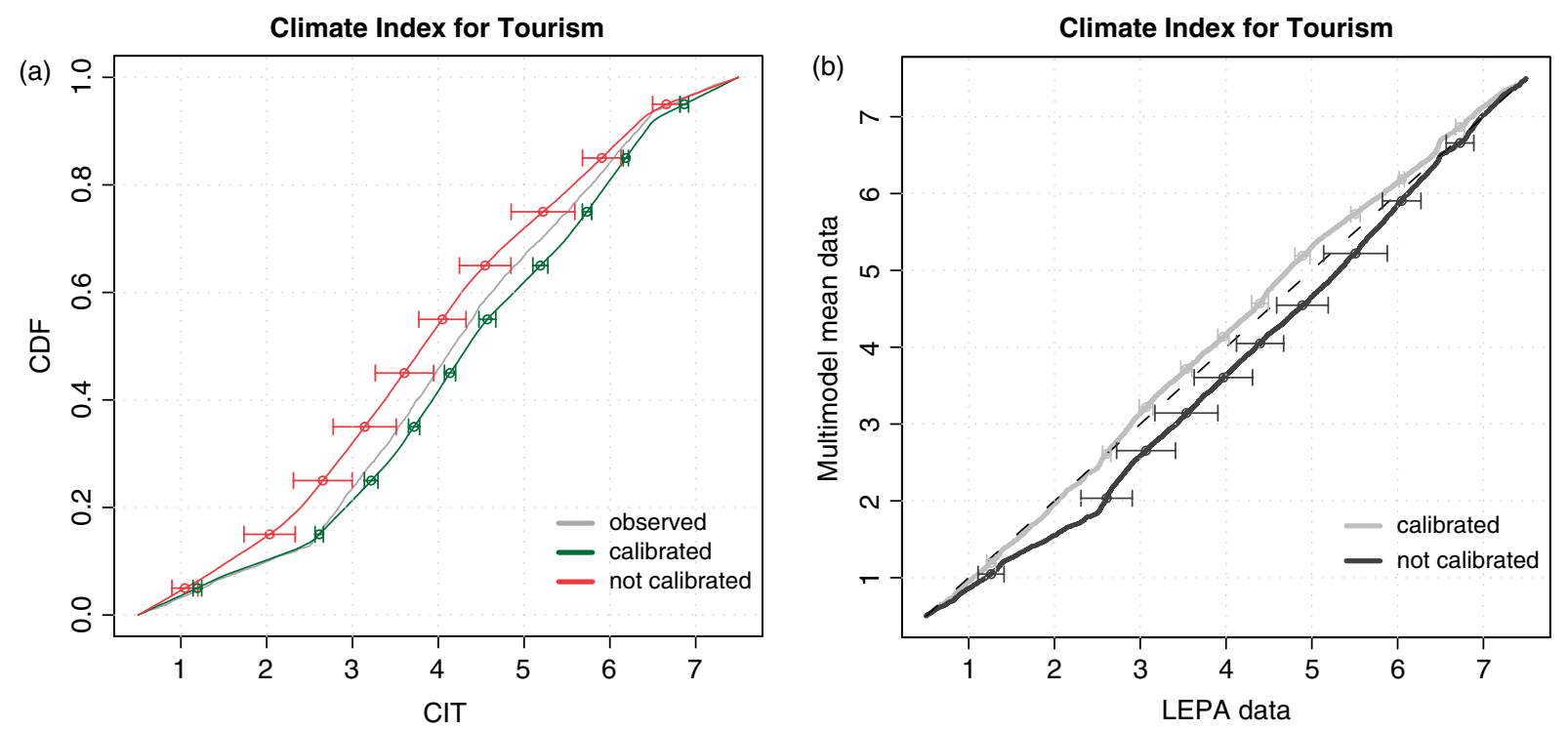

Figure 4. (a) Observed, raw and calibrated multimodel mean cumulative distribution functions, and (b) quantile-quantile plot for the climate index for tourism, and the 1994-2008 validation period. Multimodel means and their standard deviations are shown.

Table II. Percentile-wise MAE and RMSE statistical skill scores for the raw and calibrated climate index for tourism cumulative distribution functions based on multimodel mean data when compared against CIT derived from observations for the 1994-2008 validation period.

\begin{tabular}{lcccc}
\hline Variable & $\begin{array}{c}\text { MAE } \\
\text { calibrated }\end{array}$ & $\begin{array}{c}\text { MAE } \\
\text { raw }\end{array}$ & $\begin{array}{c}\text { RMSE } \\
\text { calibrated }\end{array}$ & $\begin{array}{c}\text { RMSE } \\
\text { raw }\end{array}$ \\
\hline CIT & 0.15 & 0.30 & 0.17 & 0.34 \\
\hline
\end{tabular}

unacceptable and acceptable conditions. We also perform a climatological validation for the 1994-2008 period. Figure 5 reveals a redistribution of the unacceptable, acceptable and ideal relative frequencies between the raw and calibrated databases. The statistical adjustment yields CIT values that better fit those based on observations for the unacceptable and acceptable conditions (Table III). That is, raw CITs over- and underrate the first and second classes, respectively. These biases are remarkably amended by applying the calibration method. However, calibrated CIT scores depict an overcorrection in the relative frequency for the ideal perception (Table III). As expected, the spread among the models also is reduced adequately after the application of the calibration. That is, the quantile-quantile adjustment amends possible biases and errors of each RCM when reproducing the climate of SPdP, allowing all RCMs to be safely considered equiprobable (Figures 4 and 5).

\section{Results and discussion}

4.1. Changes in annual regimes of climate potential for tourism

Once daily CIT values have been derived from the observed and simulated databases and have been adjusted

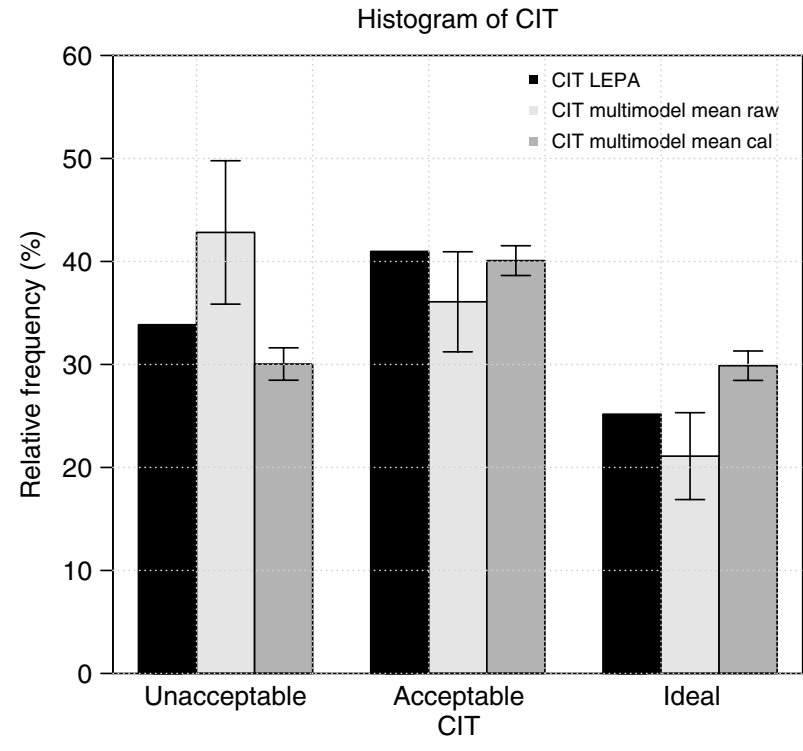

Figure 5. Observed and multimodel mean raw and calibrated relative frequency distributions $(\%)$ for the three rating classes of the climate index for tourism over the whole 15-year validation period (1994-2008). The standard deviation among the ensemble of models is also shown.

Table III. Relative frequencies (\%) for the annual distribution of the climate index for tourism of SPdP for the observed, raw and calibrated multimodel daily data and the 1994-2008 validation period. Also shown between brackets is the standard deviation of the multimodel mean regimes.

\begin{tabular}{lccc}
\hline Annual CIT & Observed & Raw & Calibrated \\
\hline Unacceptable & 34 & $43(36,50)$ & $30(28,32)$ \\
Acceptable & 41 & $36(31,41)$ & $40(39,41)$ \\
Ideal & 25 & $21(17,25)$ & $30(28,31)$ \\
\hline
\end{tabular}




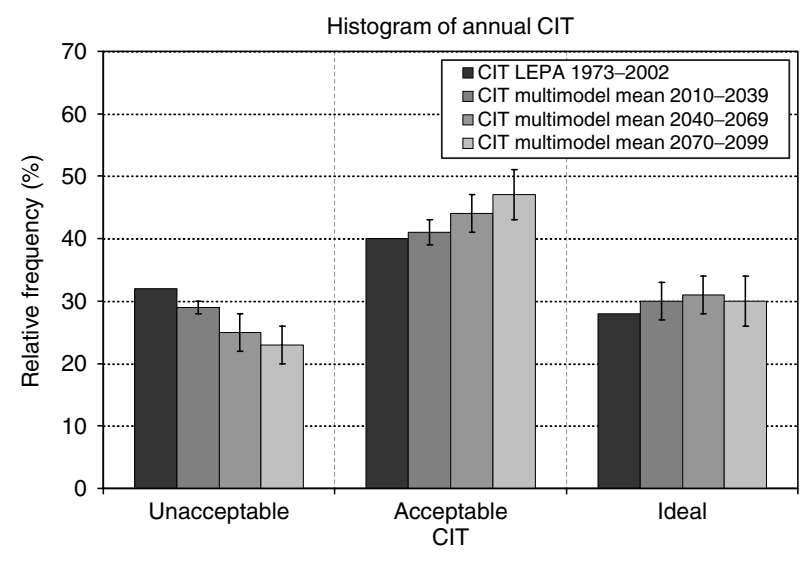

Figure 6. Relative frequency $(\%)$ of the annual mean regimes for the unacceptable, acceptable and ideal conditions of the climate resource for the present, early, mid and late time slices. Also displayed is the standard deviation of the model's ensemble.

Table IV. As in Table III, except for the present, early, mid and late future time slices. It has also been tabulated the present and projected annual mean categories for CIT.

\begin{tabular}{lcccc}
\hline Annual CIT & Present & Early & Mid & Late \\
\hline Unacceptable & 32 & $29(28,30)$ & $25(22,28)$ & $23(20,26)$ \\
Acceptable & 40 & $41(39,43)$ & $44(41,47)$ & $47(43,51)$ \\
Ideal & 28 & $30(27,33)$ & $31(28,34)$ & $30(26,34)$ \\
Mean & 4.28 & 4.36 & 4.45 & 4.50 \\
\hline
\end{tabular}

statistically to the SPdP, the present climate potential for tourism can be assessed and its future evolution explored. In particular, we examine the changes on the annual mean relative frequencies of the unacceptable, acceptable and ideal conditions for a 30-year control period (1973-2002; present) and three future multimodel mean time slices: 2010-2039 (early 21st century), 2040-2069 (mid-21st century) and 2070-2099 (late 21st century). Note that the 30 -year future periods are simple aggregations of the successive 15-year periods used in the calibration process. Figure 6 displays the distributions for the present and future time slices. The annual number of days with acceptable conditions for beach holidays dominates in the present annual mean regime - up to $40.0 \%$ of the whole amount - followed by the unacceptable $(32.4 \%)$ and ideal $(27.6 \%)$ perceptions. Furthermore, when accounting for the acceptable and optimal conditions, their relative frequencies yield a total of $67.6 \%$ of the days. The annual mean category is close to 4.3 for the present time slice (Table IV).

Climate change could have a direct impact on the spatial and temporal tourism flows over Europe. According to Perry (1993), 70-80\% of UK holidaymakers argue that the expectation of more pleasant climatic conditions is the main reason for spending their spare time. Aguiló et al. (2005) reported some of the main reasons for tourists visiting the Balearics from 1993 to 2000. Climate was ranked at the top $(76.2 \%)$, followed by the beaches $(51.2 \%)$, the price $(36.4 \%)$, the quality of the surroundings (24.5\%) or the quality of the hotels (22.2\%). Hence, the pleasant weather perception characterized by mild winters, warm and dry summers, and temperate springs and autumns for visitors is the most important asset when choosing the Balearic Islands to spend their recreation and spare time. Obviously, tourist behaviour is also affected by diverse aspects such as: political stability, socioeconomic infrastructures, environmental resources, cultural heritage, travel costs and time, natural risks and standard of living (Gössling and Hall, 2006).

Regarding future projections, Table IV and Figure 6 depict a redistribution of the annual mean CIT regimes for the unacceptable, acceptable and ideal conditions throughout the twentyfirst century. A steady drop in the annual number of days with unpleasant conditions for $3 \mathrm{~S}$ tourism is possible: the relative frequency is projected to decrease significantly from the present 32 to $23 \%$ at the end of the century (Table IV). This shift would result in a considerable increase for acceptable conditions together with a slight increment for ideal conditions as well (Table IV). Note that the variability of the projected CIT frequencies among the RCMs increases throughout the century for all categories, a natural consequence of the increasing spread with time observed in multimodel climate scenarios (Figure 6). Furthermore, a slight improvement in the overall perception of the climate asset could be expected as expressed in terms of the annual mean CIT value in SPdP (Table IV).

The European Mediterranean tourist sector is characterized by a strong seasonality with large differences in occupancy rates between the cold and warm seasons. In Spain, total tourism revenues are more than $50 \%$ higher in August than in December and the number of hotel overnight stays in August trebles those in December (INE, 2009). In addition, the peak season demand for beach-based tourism also is influenced strongly by state holidays and not just the weather. Previous studies have pointed out a future projected imbalance between institutional and natural seasonality for the European Mediterranean region (Amelung and Viner, 2006; Amelung et al., 2007; Hein et al., 2009). Therefore, further exploration of this issue by means of the seasonal CIT scores emerges as an important topic.

\subsection{Changes in seasonal regimes of climate potential for tourism}

As mentioned above, several studies have indicated that future summery peak season (i.e. June, July and August) weather conditions could deteriorate in the European Mediterranean area, whereas it could improve in western and northern Europe. Climate change impacts over the latter regions during the peak season, which are currently the major source of tourists for the Mediterranean, might imply a major modification in the tourism traffic and might lead to more domestic tourism in northwestern Europe. However, climate conditions for the shoulder seasons (i.e. spring and autumn) are expected to improve for the European Mediterranean countries during this century (Amelung and Viner, 2006; Amelung et al., 2007; 
Hein et al., 2009). This fact could help to deseasonalize their tourist industries; seasonality is currently one of the main handicaps to overcome for the tertiary sector. We define seasons as: winter (December, January and February), spring (March, April and May), summer (June, July and August), and autumn (September, October and November).

Projected CIT indicates a constant decrease in winter relative frequencies for the unacceptable weather perception which would be mainly redistributed as acceptable conditions (Table V, Figure 7(a)). This wintry redistribution of the climate asset could result in clearly benefiting the latter, which are anticipated to exceed the unacceptable conditions for the late twentyfirst century. In springtime, an overall growth in the relative frequencies for the optimal conditions is foreseen, at the expense of a continuous decrease in the average number of days with unacceptable categories and a steady trend

Table V. As in Table IV, except for the winter distribution of the climate index for tourism of SPdP.

\begin{tabular}{lcccc}
\hline Winter CIT & Present & Early & Mid & Late \\
\hline Unacceptable & 61 & $54(50,58)$ & $48(40,56)$ & $45(37,53)$ \\
Acceptable & 32 & $42(38,46)$ & $45(37,53)$ & $46(36,56)$ \\
Ideal & 7 & $4(1,7)$ & $7(2,12)$ & $9(3,15)$ \\
Mean & 3.41 & 3.36 & 3.50 & 3.61 \\
\hline
\end{tabular}
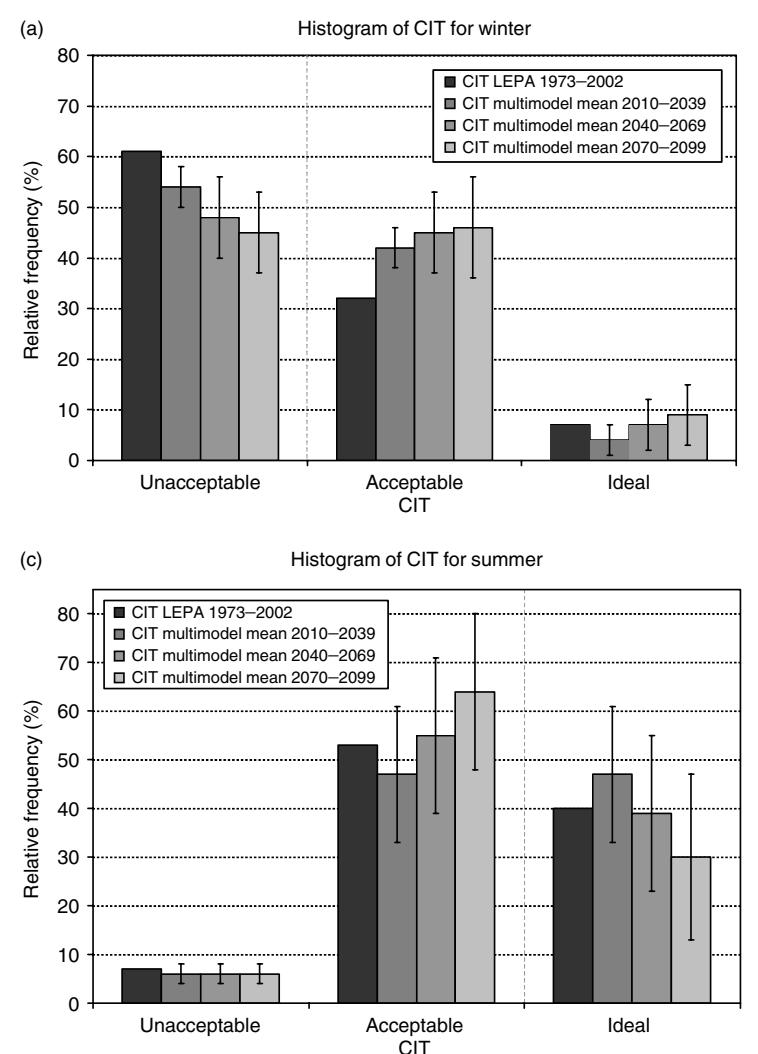

Table VI. As in Table IV, except for the spring distribution of the climate index for tourism of SPdP.

\begin{tabular}{lcccc}
\hline Spring CIT & Present & Early & Mid & Late \\
\hline Unacceptable & 34 & $30(26,34)$ & $25(20,30)$ & $21(17,25)$ \\
Acceptable & 37 & $38(32,44)$ & $38(32,44)$ & $36(30,42)$ \\
Ideal & 29 & $32(25,39)$ & $37(29,45)$ & $43(36,50)$ \\
Mean & 4.27 & 4.37 & 4.57 & 4.77 \\
\hline
\end{tabular}

Table VII. As in Table IV, except for the summer distribution of the climate index for tourism of SPdP.

\begin{tabular}{lcccc}
\hline Summer CIT & Present & Early & Mid & Late \\
\hline Unacceptable & 7 & $6(4,8)$ & $6(4,8)$ & $6(4,8)$ \\
Acceptable & 53 & $47(33,61)$ & $55(39,71)$ & $64(48,80)$ \\
Ideal & 40 & $47(33,61)$ & $39(23,55)$ & $30(13,47)$ \\
Mean & 4.92 & 5.23 & 5.07 & 4.91 \\
\hline
\end{tabular}

for the acceptable perceptions (Table VI, Figure 7(b)). Figure 7(c) depicts that the summery number of days with ideal conditions is expected to significantly increase at the expense of the satisfactory climate perception for the early century, but the opposite is foreseen thereafter. The unacceptable conditions could remain nearly constant (Table VII). Note that the variability among CIT scores based on models presents its greatest value in
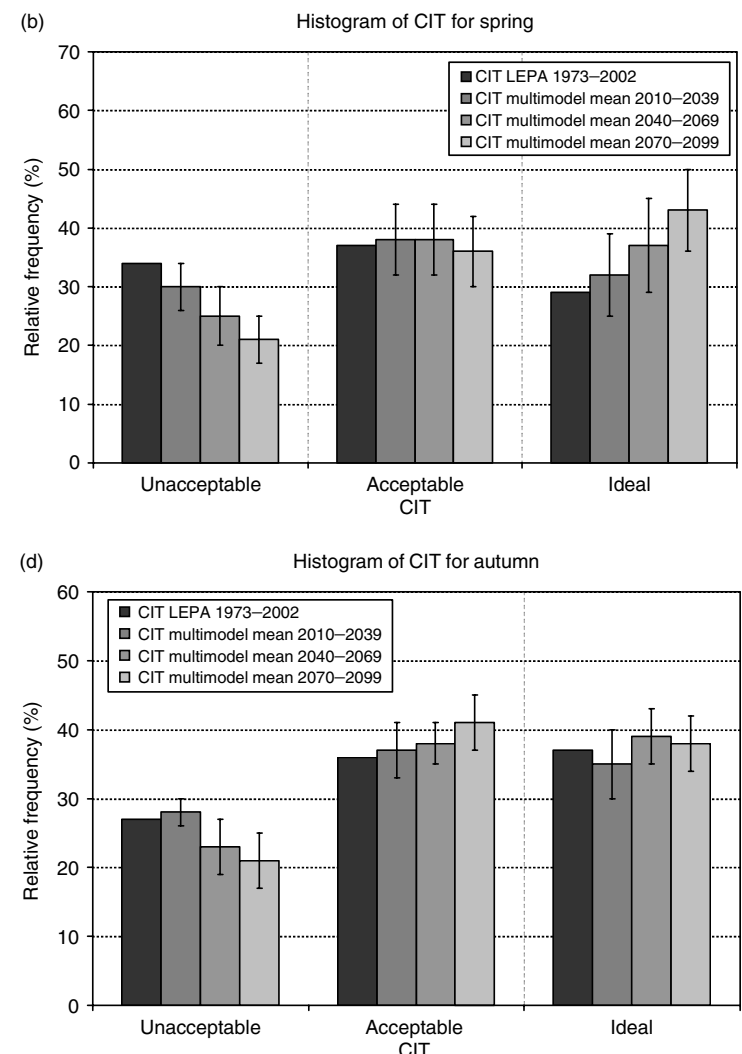

Figure 7. Relative frequency (\%) of (a) winter, (b) spring, (c) summer, and (d) autumn mean regimes for the unacceptable, acceptable and ideal conditions of the climate resource for the present, early, mid- and late-twentyfirst time slices. Also displayed is the standard deviation of the model's ensemble. 
Table VIII. As in Table IV, except for the autumn distribution of the climate index for tourism of SPdP.

\begin{tabular}{lcccc}
\hline Autumn CIT & Present & Early & Mid & Late \\
\hline Unacceptable & 27 & $28(26,30)$ & $23(19,27)$ & $21(17,25)$ \\
Acceptable & 36 & $37(33,41)$ & $38(35,41)$ & $41(37,45)$ \\
Ideal & 37 & $35(30,40)$ & $39(35,43)$ & $38(34,42)$ \\
Mean & 4.49 & 4.44 & 4.63 & 4.66 \\
\hline
\end{tabular}

summer (Figure 7(c)). In autumn, a moderate increase for the acceptable conditions is projected together with a noticeable decrease in the unpleasant categories. A small increase in the relative frequency for ideal climate perceptions could be expected from mid-century as well (Table VIII, Figure 7(d)). For the shoulder seasons, the overall projected increase in the relative frequencies for the acceptable and/or ideal conditions is due to the decrease in the unacceptable ones. Finally, seasonal CIT mean scores would reveal a general improvement in future mean regimes of the climate asset for all seasons when compared against the present values (last rows in Tables V-VIII).

The climate resource very likely will remain an important push and pull factor for the tourism flows around Europe in the future. Northwestern European countries are currently the major tourism source for the Balearic Islands. As an example, European Union Community (EU) countries were the leading source for the inflow of foreign visitors in the Palma municipality during 2008, with more than one million overnight stays. Germany and the United Kingdom were the main markets, contributing more than $42 \%$ and close to $27 \%$ of the total amount of tourists, respectively (INE, 2009). In addition, the percentage of nights spent by EU visitors was close to $64 \%$ of the annual amount in summer, while the occupancy rate due to domestic tourism was only $25 \%$ (INE, 2009). Hence, summer peak visitation levels could be affected negatively if a worsening of the ideal weather perception occurs throughout the century. However, the possibility of further expansion of the $3 \mathrm{~S}$ tourism climate asset into the shoulder seasons could arise, owing to the projected increase in the number of days with acceptable and/or ideal conditions. In that case, higher tourism revenues in spring and autumn would alleviate partially the economic losses for the summery season as climate resource perception would change.

For example, the current employment pattern in the Balearics is strongly bound to the tourist demand: $76,2 \%$ of the active population is directly employed in the tertiary sector and this sector aggregates up to $72.8 \%$ of the whole inland companies. For Palma municipality, up to $83 \%$ of the employees worked directly in it, and more than $81 \%$ of the companies dealt with the service sector in 2007 (Palma Agenda Local 21, 2008). The management of such a seasonally dependent employment pattern requires major efforts for the inland social and economic structures. Furthermore, SPdP is devoted completely to a mass tourism model resulting in high environmental costs.

\subsection{Changes in monthly regimes of climate potential} for tourism

To associate the annual flow of $3 \mathrm{~S}$ tourism and climate perceptions, we compare the monthly average visitation levels during the 1999-2008 period for the Palma municipality which is the smallest geographical unit for which attendance information is available (INE, 2009) to the present and future mean CIT for each month. As already pointed out by Amelung and Viner (2006), this is not an attempt to bind particular weather conditions and visitation levels in the same specific years, but to show the link between the climate resource and attendance levels throughout the annual cycle. Thus, we illustrate qualitatively the climate change effects on tourism flows by means of the CIT projections for SPdP. Furthermore, the current dominance of the beach-based outdoor activities enables us to use SPdP as a measure for further verifying CIT: the occupancy rates act as a suitable demand indicator to measure $3 \mathrm{~S}$ tourist satisfaction with climate conditions. Therefore, the limitations indicated by De Freitas et al. (2008), who originally examined CIT for a relatively narrow tourist marked (i.e. young adults) and over a restricted spatial coverage (i.e. only one country) can be alleviated. This procedure accounts for a wide segment of the tourist market (i.e. including different ages and family status) and for a larger spatial visitor source coverage as well (i.e. several European countries).

Present climate potential for tourism is characterized by a peak frequency in August for the acceptable conditions (Figure 8(a)), with up to $61 \%$ of the number of days. Furthermore, the acceptable perception for carrying out beach-based leisure activities has its highest percentages from May to October. This period coincides with the high visitation period for SPdP, defined as the six months with the largest occupancy rates. Ideal conditions show a bimodal distribution, with the first maximum located in June - slightly above $51 \%$ of June days - and the second found in September, up to $49 \%$ of total days. Likewise, the optimal distribution shows the largest scores from May to October as well (Figure 8(b)). However, the month with the largest peak demand does not match these months, exhibiting the highest ideal climate conditions for $3 \mathrm{~S}$ spare time. Figure 8 shows that the highest visitation level is found in August, owing to the temporal coincidence with state holidays (i.e. school holidays that permit family travel). Therefore, the peak demand is observed to occur outside of the time (June) when climate conditions are mostly optimal.

Even if this fact confirms the strong influence of institutional seasonality on attendance levels, the high visitation period spans over the six months in which the CIT rates above $75 \%$ of days with acceptable or optimal conditions. During this period, more than $70 \%$ of the total annual amount of overnight stays are spent in the Palma municipality (INE, 2009). Therefore, climate 
(a)

Visitation and acceptable CIT in Palma de Mallorca municipality

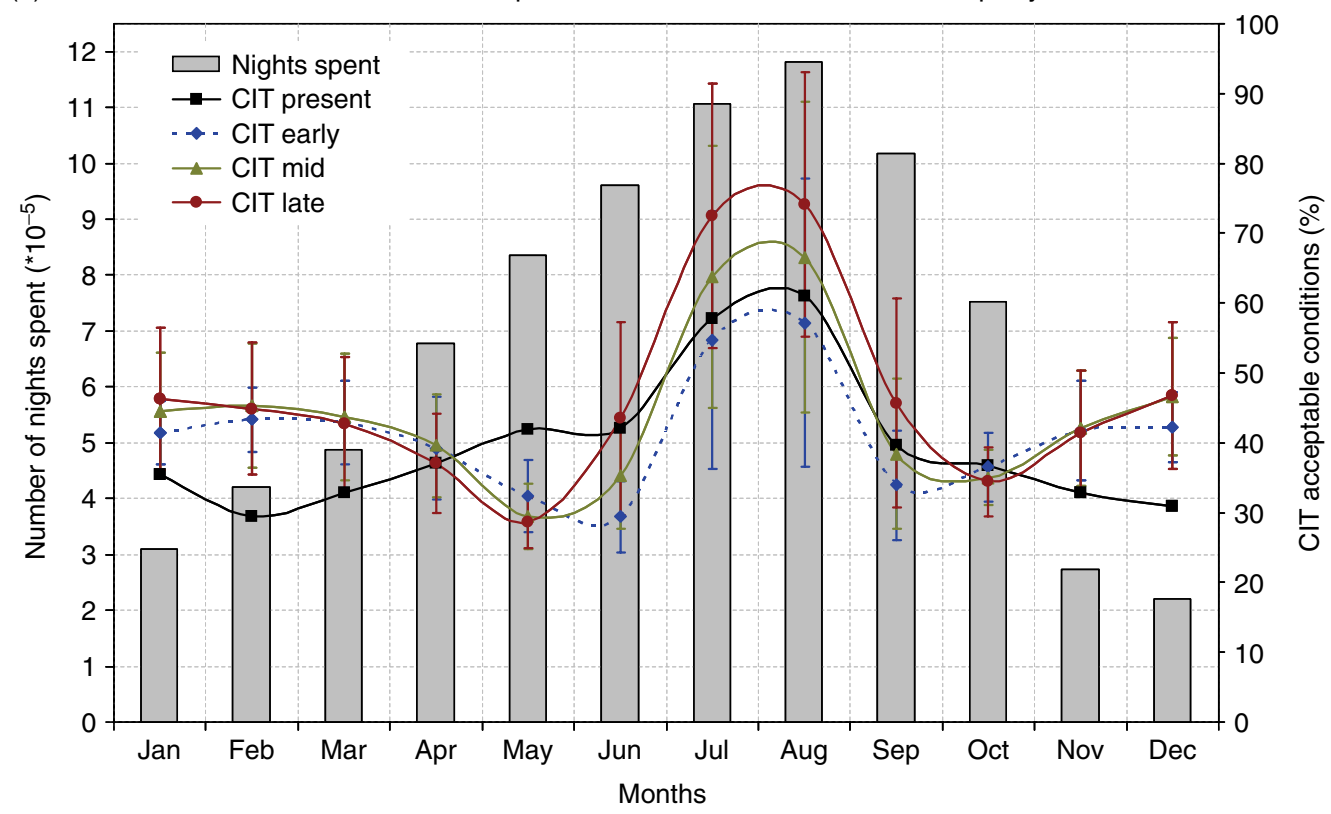

(b)

Visitation and acceptable CIT in Palma de Mallorca municipality

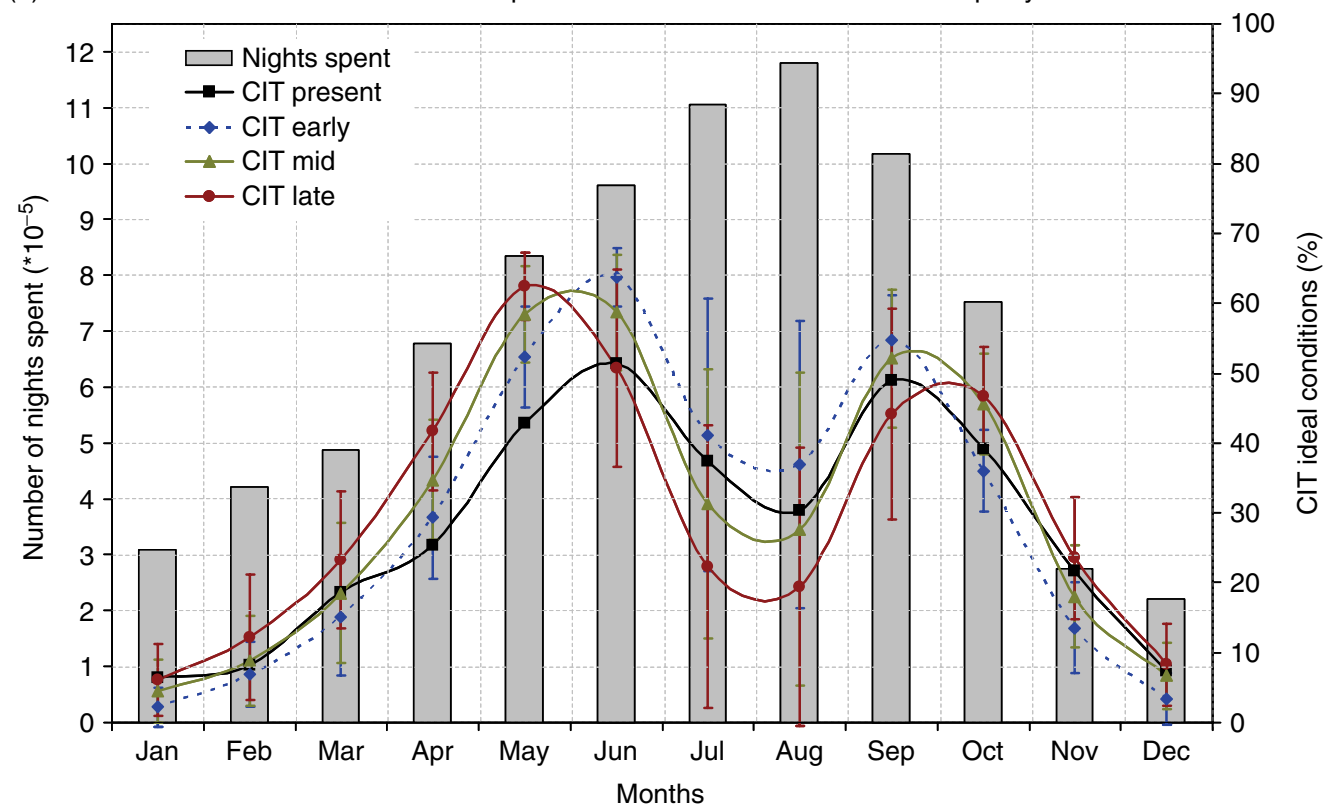

Figure 8. Monthly average visitation levels for the 1999-2008 period in Palma county and climatic average CIT scores per month for the present (1973-2002), early (2010-2039), mid (2040-2069) and late (2070-2099) time slices: (a) Acceptable conditions, and (b) Ideal conditions. Also displayed is the standard deviation of the model's ensemble.

conditions are revealed as the current preference of tourism over other factors that determine the attractiveness of this area. These results strengthen the previous verification task of the CIT carried out by comparing measures of tourist satisfaction - through a questionnaire survey - against weather conditions monitored on-site (De Freitas, 2008).

With regard to the projected tourism potential in SPdP, Figure 8(a) depicts a decrease in the percentage of days per month with acceptable conditions for the entire high attendance period (i.e. from May to October) and the early century as well as, a remarkable increase for the off-season months. Furthermore, the peak of the monthly
CIT distribution is projected to oscillate throughout the century. That is, first slightly diminishing the frequency of acceptable conditions (from 61 to 57\% in August) but, from mid-century, exceeding remarkably the present maximum frequency (up to $74 \%$ of August days for late-century) at the expense of the shoulder months. The projected decrease in the relative percentage of the present number of days with acceptable conditions for May, June and September until the end of the century can be attributed to the shift of their relative frequencies towards the optimal class.

For ideal conditions, Figure 8(b) illustrates the maintenance of the bimodal distribution. For the early century, 
an overall increment in the number of days per month with optimal conditions is expected during the whole high-visitation period. Later, a remarkable decrease is foreseen for the summery season during the current highest attendance months, July and August. That is, the relative frequencies for ideal climate perceptions during both months could fall up to 22 and $19 \%$ at the end of the twentyfirst century, respectively. A shift of the ideal categories towards the shoulder seasons can be expected from mid-century. The improvement in the relative frequencies for ideal perceptions is projected to be more marked for late spring and early to mid-autumn (Figure 8(b)), anticipating a general displacement of ideal conditions towards the beginning and ending of the high-visitation period. These projected changes would result in important consequences for the current seasonally adjusted tourism flows for SPdP, which is consistent with the findings of previous research devoted to analyses at large scale (Amelung and Viner, 2006; Amelung et al., 2007; Hein et al., 2009).

\section{Conclusions and remarks}

An assessment of the present climate potential for tourism over SPdP and an exploration of its possible future evolution in an era of climate change have been carried out. SPdP is one of the major resorts in the whole European Mediterranean basin. Its main socioeconomic activities are focussed on a beach-based mass tourism model. Key issues for the Consortium of Platja de Palma are: sustainability, global environmental change and social and residential cohesion. Basically, the search of a new model for a leading exhausted destination. Therefore, the evaluation of climate change impacts over this region is one of the main concerns for the Consortium.

Observed and simulated daily series of maximum temperature, precipitation, relative humidity, cloudiness and wind speed have been used in order to apply a secondgeneration climate index for tourism. We have adopted a multimodel ensemble approach to assess the uncertainties arising from model errors and their boundary conditions. To use this regional database properly at such local scales, we have applied a quantile-quantile adjustment to the CIT series, based on individual RCM daily outputs. Results show an overall improvement in reproducing the present climate potential for tourism for a validation period (i.e. 1994-2008) when using calibrated instead of raw CIT daily series. Then, the climate potential for tourism has been explored in terms of the differences among the CIT categories on their annual and seasonal mean regimes by comparing a present and three future time slices. Projections indicate a remarkable decrease in the relative frequency of ideal conditions for carrying out $3 \mathrm{~S}$ leisure activities during the summery peak season throughout the century, but the opposite for acceptable categories. Furthermore, an overall increase in the frequencies of the satisfactory and/or optimal climate perceptions is expected for the shoulder seasons.
The current summery concentration of the tourist demand in SPdP cannot be attributed only to the climate asset but to other factors as well. One of the most important of these is the temporal coincidence of the natural and institutional seasonality. However, owing to the preeminence of beach-based tourism activities, we have considered SPdP as a suitable location for using occupancy rates as an indicator of the suitability of climate resource. By correlating monthly present CIT values and current tourist attendance in Palma municipality, we have been able to further validate this indicator. Although CIT is theoretically sounded and empirically tested, it has certain limitations. Originally, CIT was only verified for a relatively narrow tourist market segment and a comparatively small spatial domain. Results reveal that the current high-visitation period coincides with those months that exhibit a percentage of days per month with an acceptable or ideal climate perception above $75 \%$.

Projected monthly tourism potential suggests important consequences on the seasonally adjusted tourism sector for SPdP owing to the shift of ideal conditions from the present highest attendance months to the beginning and ending of the high-visitation period. Therefore, state, regional and local policy makers should be able to address possible climate change impacts on the current status of its tertiary sector. This industry is currently the main driving force of employment and gross income for the inhabitants of the region. Furthermore, such a mass tourism destination is the main competitor for agricultural activities over the natural resources. The projected shift in the ideal climate perception for $3 \mathrm{~S}$ tourism could offer new opportunities for a corporate restructuring of the tourist sector. A deseasonalisation from the current summery peak concentration could alleviate the stress produced by a tourism destination with high environmental costs. In SPdP, the diversification of tourist activity could be encouraged either by introducing new leisure activities not so strongly dependent on beach holidays during the peak season, or by shifting these towards the shoulder seasons. Finally, it must not be forgotten that although climate change is a problem of global concern, its effects become more apparent locally. Within this context, further development and application at local scales of climate indices for different kinds of tourism remains as an issue of considerable interest.

\section{Acknowledgements}

The authors express their thanks and appreciation to Dr Charles A. Doswell III, Visiting Professor at UIB, for his valuable comments and suggestions on this work. Prof. Glenn McGregor, associate editor of the International Journal of Climatology, and the anonymous reviewer are deeply acknowledged for their valuable comments which helped to improve the quality of this manuscript. The Spanish Agency of Meteorology (AEMET) is acknowledged for providing the automatic weather station data. This work has been sponsored by El Consorci de la Platja de Palma with funds provided by the Balearic 
Islands and the Spanish State Governments through the Institut Mediterrani d'Estudis Avançats (IMEDEA; CSIC-UIB), and by the CGL2008-01271/CLI (MEDICANES) Spanish project, which is partially supported with FEDER funds. The authors also acknowledge the ENSEMBLES project, funded by the European Commission's 6th Framework Programme, through contract GOCE-CT-2003-505539.

\section{References}

Aguiló E, Alegre J, Sard M. 2005. The persistence of the sun and sand tourism model. Tourism Management 26(2): 219-231.

Akima H. 1978. A Method of Bivariate Interpolation and Smooth Surface Fitting for Irregularly Distributed Data Points. ACM Transactions on Mathematical Software 4: 148-164.

Akima H. 1996. Algorithm 761: scattered-data surface fitting that has the accuracy of a cubic polynomial. ACM Transactions on Mathematical Software 22: 362-371.

Amengual A, Romero R, Alonso S. 2008. Hydrometeorological ensemble simulations of flood events over a small basin of Mallorca Island, Spain. Quarterly Journal of the Royal Meteorological Society 134: 1221-1242. DOI: 10.1002/qj.291.

Amengual A, Homar V, Romero R, Alonso S, Ramis C. 2011. A statistical adjustment of regional climate model outputs to local scales: Application to Platja de Palma, Spain. J. Climate. DOI 10.1175/JCLI-D-10-05024.1.

Amelung B, Nicholls S, Viner D. 2007. Implications of global climate change for tourism flows and seasonality. Journal of Travel Research 45: $285-296$.

Amelung B, Viner D. 2006. Mediterranean tourism: exploring the future with the tourism climatic index. Journal of Sustainable Tourism 14(4): 349-366.

ASHRAE. 2004. Thermal Environmental Conditions for Human Occupancy. ASHRAE Standard 55-2004. ASHARE Inc.: Atlanta, GA, USA.

Bigano A, Hamilton JM, Tol RSJ. 2006. The impact of climate on holiday destination choice. Climatic Change 76: 389-406.

De Freitas CR. 1985. Assessment of human bioclimate based on thermal response. International Journal of Biometeorology 29 97-119.

De Freitas CR. 1990. Recreation climate assessment. International Journal of Climatology 10: 89-103.

De Freitas CR, Scott D, McBoyle G. 2008. A second generation climate index for tourism (CIT): specification and verification. International Journal of Biometeorology 52: 399-407.

Gössling S, Hall M. 2006. Uncertainties in predicting tourist flows under scenarios of climate change. Climatic Change 79: 163-173.

Gual M, Perelló J, Ramis C. 2002. La isla de calor urbana en Palma de Mallorca. Revista Española de Física 16: 39-43.

Guijarro JA. 1986. Contribución a la Bioclimatología de Baleares.
Ph.D. Thesis. Available at the library of the Universitat de les Illes Balears (UIB), Palma de Mallorca, Spain.

Hein L, Metzger MJ, Moreno A. 2009. Potential impacts of climate change on tourism; a case study for Spain. Current Opinion in Environmental Sustainability 1: 170-178.

Hewitt CD, Griggs DJ. 2004. Ensembles-based Predictions of Climate Changes and their Impacts. EOS, Transactions American Geophysical Union 85: 566. DOI: 10.1029/2004EO520005.

Homar V, Ramis C, Romero R, Alonso S. 2010. Recent trends in temperature and precipitation over the Balearic Islands (Spain). Climatic Change 98: 199-211.

INE. 2009. Encuesta de la ocupación hotelera. Spanish Statistical Institute (INE; further information at http://www.ine.es).

IPCC. 2007. Climate Change 2007: The Physical Science Basis. Contribution of Working Group I to the Fourth Assessment Report of the Intergovernmental Panel on Climate Change. Solomon S, Qin D, Manning M, Chen Z, Marquis M, Averyt KB, Tignor M, Miller HL (eds). Cambridge University Press: Cambridge, United Kingdom and New York, NY, USA; 996.

Lise W, Tol RSJ. 2002. Impact of climate on tourism demand. Climatic Change 55(4): 429-449.

Maddison D. 2001. In Search of Warmer Climates? The Impact of Climate Change on Flows of British Tourists. Climatic Change 49(1/2): 193-208.

Matzarakis A, Rutz F. 2007a. RayMan: a tool for tourism and applied climatology. Developments in Tourism Climatology 129-138. In Matzarakis A, de Freitas CR, Scott D. (eds.) 2007: Developments in Tourism Climatology. Commission Climate, Tourism and Recreation. International Society of Biometeorology. ISBN: 978-3-00-024110-9.

Matzarakis A, Rutz F, Mayer H. 2007b. Modelling radiation fluxes in simple and complex environments - application of the RayMan model. International Journal of Biometeorology 51: 323-334.

Mieczkowski Z. 1985. The tourism climatic index: a method of evaluating world climates for tourism. The Canadian Geographer 29(3): 220-233.

Nakicenovic N. 2000. Emissions Scenarios. A Special Report of Working Group III of the Intergovernmental Panel on Climate Change. Cambridge University Press: 599.

Palma Agenda Local 21. 2008. El desenvolupament sostenible del municipi de Palma: descripció de l'entorn socioeconòmic. Ajuntament de Palma de Mallorca, Illes Balears, Spain (available at http://al21.palmademallorca.es)

Perry A. 1993. Climate and weather information for the package holiday-maker. Weather 48(12): 410-414.

Romero R, Sumner G, Ramis C, Genovés A. 1999. A classification of the atmospheric circulation patterns producing significant daily rainfall in the Spanish Mediterranean area. International Journal of Climatology 19: 765-785.

Tudurí E, Ramis C. 1997. The environments of significant convective events in the western Mediterranean. Weather and Forecasting 12 : 294-306.

Viner D. 2006. Tourism and its interactions with climate change. Journal of Sustainable Tourism 14(4): 317-322. 